\title{
BMJ Open Epidemiological features of human brucellosis in Tongliao City, Inner Mongolia province, China: a cross- sectional study over an 11-year period (2007-2017)
}

$\mathrm{Di} \mathrm{Li}^{1}{ }^{1}$ Lifei Li, ${ }^{2}$ Jingbo Zhai, ${ }^{3}$ Lingzhan Wang, ${ }^{4}$ Bin Zhang (D) ${ }^{5}$

To cite: Li D, Li L, Zhai J, et al. Epidemiological features of human brucellosis in Tongliao City, Inner Mongolia province, China: a cross-sectional study over an 11-year period (2007-2017). BMJ Open 2020;10:e031206. doi:10.1136/ bmjopen-2019-031206

- Prepublication history and additional material for this paper are available online. To view these files, please visit the journal online (http://dx.doi. org/10.1136/bmjopen-2019031206).

Received 24 April 2019

Revised 24 November 2019

Accepted 25 November 2019

Check for updates

(C) Author(s) (or their employer(s)) 2020. Re-use permitted under CC BY-NC. No commercial re-use. See rights and permissions. Published by BMJ.

For numbered affiliations see end of article.

Correspondence to

Dr Bin Zhang;

binz361@126.com

\section{ABSTRACT}

Objectives To describe the epidemiology of human brucellosis in the past decade and provide evidence of disease control in Tongliao city, which is one of the highest-risk areas of human brucellosis in Inner Mongolia province, China.

Design Cross-sectional study.

Participants Clinically and bacteriologically confirmed human brucellosis cases.

Primary and secondary outcome measures An analysis of the reported cases of human brucellosis during 2007-2017 was carried out to describe the age, sex and occupational distributions of the cases. The time series analysis model and the geographical information system were explored to describe the seasonality and spatiotemporal distribution, respectively, at the county level.

Results A total of 13938 cases of human brucellosis was collected in Tongliao from 2007 to 2017; the majority was aged 25 years to 59 years $(85.4 \%)$ and the male-to-female ratio was $2.64: 1$; most of them were agriculturalists $(81.9 \%)$ and pastoralists $(12.4 \%)$. The incidence rates increased dramatically from 9.22/100 000 in 2007 to $69.16 / 100000$ in 2011 with an annual increase of $14.99 \%$. They decreased during 2012-2016 (annual decrease of $8.37 \%$ ) and rose again in 2017 (44.32/100 000). The disease peaked during March-July, with a clear periodicity and trend of monthly anterior displacement since 2012. Jarud Banner, the region located in the northwest of Tongliao, had the highest accumulated incidence rate $(130.1 / 100000)$ compared with other counties. The high-risk regions were spread from the north-west to the south and east of Tongliao during the past decade.

Conclusions The prevalence of human brucellosis in Tongliao was aggravated during the past decade and peaked during March-July. High-risk areas were mainly concentrated in the counties with extensive prairies and livestock.

\section{INTRODUCTION}

Brucellosis is a highly contagious zoonotic disease caused by Brucella spp and poses great challenges to public health, particularly in developing countries. ${ }^{12}$ It is rarely
Strengths and limitations of this study

- This is the first study that was focused on the epidemiological characteristics of human brucellosis during the past 11 years in Tongliao, which is one of the highest-risk areas in Inner Mongolia, China.

- Demographic data, seasonality and spatiotemporal distribution of reported brucellosis cases were explored to provide evidence for strategies of disease control in Tongliao.

- The data used in the present study might be influenced by under-reporting, misdiagnosis and incomplete information as a result of passive public health surveillance.

- The densities of livestock, meat yield, slaughter amount, environment and pathogen types were not available in the present study, and these data should be taken into account for brucellosis transmission and prediction as risk factors.

fatal, but has important impacts on the livestock economy due to loss of production in international markets. ${ }^{3}$ Human brucellosis is commonly transmitted from infected livestock directly or indirectly, and is characterised by acute febrile illness, inflammation of the genitals, sterility, spontaneous miscarriage and lymphatic system lesions, amounting to more than half a million new cases annually worldwide. ${ }^{4}$ It has been a huge problem for hyperendemic northern China since the first report in $1905 .^{5}$ There was nationwide reporting of human brucellosis in China in the 1960s, and the incidence was quite severe before the 1980s, followed by a decrease for 15 years due to the domestic animal brucellosis control and eradication programme. ${ }^{6}$ However, the epidemic situation of the disease has increased sharply since 1995, and about 20 000-50 000 new cases are reported every 
year with an annual increase of $7.8 \%$ during the last 10 years in China. ${ }^{7}$ Increased livestock trading, the growing demand for meat consumption, absence of quarantine or pasteurisation of livestock products, and rapid movement of people during the past decade has given rise to increased risk of infection among the population having direct or indirect contact with livestock. ${ }^{8}$

Inner Mongolia is the most important province in north-east China for livestock husbandry, and has been contributing about $40 \%$ of new cases of human brucellosis annually. ${ }^{9}$ New focus on human brucellosis has been spread all over Inner Mongolia, and the incidence increased from 0.34 per million in 2002 to 3.33 per million in $2006 .{ }^{410}$ Most of the patients in Inner Mongolia are farmers or herdsmen, and are commonly infected from Brucella melitensis infected sheep (92\%). ${ }^{11}$ Besides, Tongliao, a semiagricultural and semipastoral area located in eastern Inner Mongolia, has been one of the most high-risk areas of human brucellosis with an incidence of 10-100 per 100000 during 2006$2010 .{ }^{9}$ It is reported that the incidence of human brucellosis among the high-risk groups (population engaged in agricultural cultivation, grazing, slaughtering, etc) in Tongliao city was as high as $11.4-49.8 \%$ from 2010 to $2014 .{ }^{12}$ Previous research has expounded the spatiotemporal distribution of human brucellosis in Inner Mongolia; however, few studies have explored the high-risk areas at the county level in recent years. In addition, since human brucellosis is strongly associated with work and seasonality, the characteristics of the new human brucellosis epidemic in Tongliao should be known, so as to provide evidence for disease control strategies.

In the present study, information on the reported cases of human brucellosis at the county level in Tongliao, Inner Mongolia province, China, from 2007 to 2017 were collected, and their epidemiological features were analysed.

\section{METHODS}

\section{Study area}

Tongliao $\left(42^{\circ} 15^{\prime}-45^{\circ} 41^{\prime} \mathrm{N}\right.$ and $\left.119^{\circ} 15^{\prime}-123^{\circ} 43^{\prime} \mathrm{E}\right)$ is located in the equatorial zone in eastern Inner Mongolia in China, at an altitude of $120-1400 \mathrm{~m}$ and continental area of $59835 \mathrm{~km}^{2}$. It is divided into eight counties with a total population of 3.16 million. It has an annual precipitation of $305-485 \mathrm{~mm}$, and its average annual temperature is $0^{\circ} \mathrm{C}-6^{\circ} \mathrm{C}$. The region is a major foodstuff and livestock (mainly sheep, cattle and pigs) production zone in China, and the husbandry contributes to $42.4 \%$ of the total revenue of Tongliao. The communities of the area are mainly pastoralists and agriculturalists.

\section{Data collection}

Data for this retrospective, non-experimental study were obtained from the National Disease Prevention Information System, and were supplied by the First Institute of Endemic Diseases Prevention in Jilin Province, China.
Information on human brucellosis cases in Tongliao city was collected from January 2007 to December 2017 according to the monthly reports of surveillance, a period that the complete data could be available and was consistent with the national conditions of China's 10-year statistics for the formulation of control strategies for the next decade. All the data in the current study were publicly open and supplied in an anonymous format, without violation of any personal privacy.

Human brucellosis was diagnosed through a combination of epidemiological exposure (contact history of Brucella or living in endemic areas) and clinical manifestations (undulant fever, fatigue, sweats, arthritis, arthralgia, myalgia, splenomegaly, hepatomegaly, etc), and confirmed by positive results of presumptive laboratory tests (plate agglutination test, Rose Bengal plate test, serum agglutination test, bacterial isolation, etc), according to the '2007 Diagnostic Criteria of Brucellosis (WS268-2007)' of the Chinese Ministry of Health.

\section{Statistical analysis}

The data were entered into a Microsoft Excel spreadsheet, and the demographic data were analysed using simple descriptive statistics. The cumulative incidence was explored to describe the prevalence and frequency of the disease during the study period. The spatiotemporal distribution maps of human brucellosis based on county were plotted using a geographical information system through R-Project software (MathSoft, Auckland, New Zealand). The monthly number of human brucellosis cases was drawn on a thermograph to analyse the seasonality. All further statistical analyses were conducted by SPSS V.18.0 (SPSS, Chicago, USA).

\section{Patient and public involvement}

Patients were not involved in the present study. The results of the main study were presented to study participants at the National Disease Prevention Information System of China through a monthly report.

\section{RESULTS}

\section{Demographic data of human brucellosis in Tongliao}

A total of 13938 cases of human brucellosis from January 2007 to December 2017 was reported in Tongliao, with an average of $1268 \pm 555$ cases per year. For all of the diagnosed cases, $72.9 \%(n=10162)$ and $30.2 \%(n=4214)$ of patients were confirmed by serological tests and bacterial culture, respectively. The median age of the cases was 42 (1-85) years (average of $41.81 \pm 12.22$ years). The age distribution is shown in figure $1 \mathrm{~A}$ and online supplementary table $\mathrm{S} 1$, and most of the cases were 25-59 years old with a percentage of $85.44 \%$, although the susceptibility of human brucellosis was generally considered equal in all populations. The proportions of children ( $<15$ years old) and elderly ( $\geq 60$ years old) were $1.43 \%$ and $7.21 \%$, respectively. The number of male patients $(n=10,114)$ was much more than female 

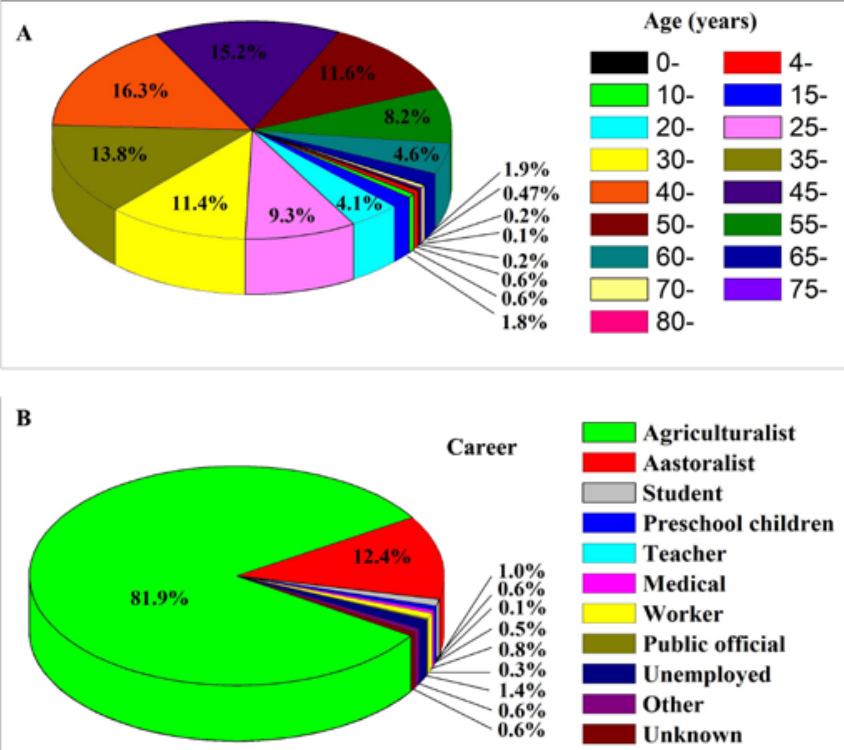

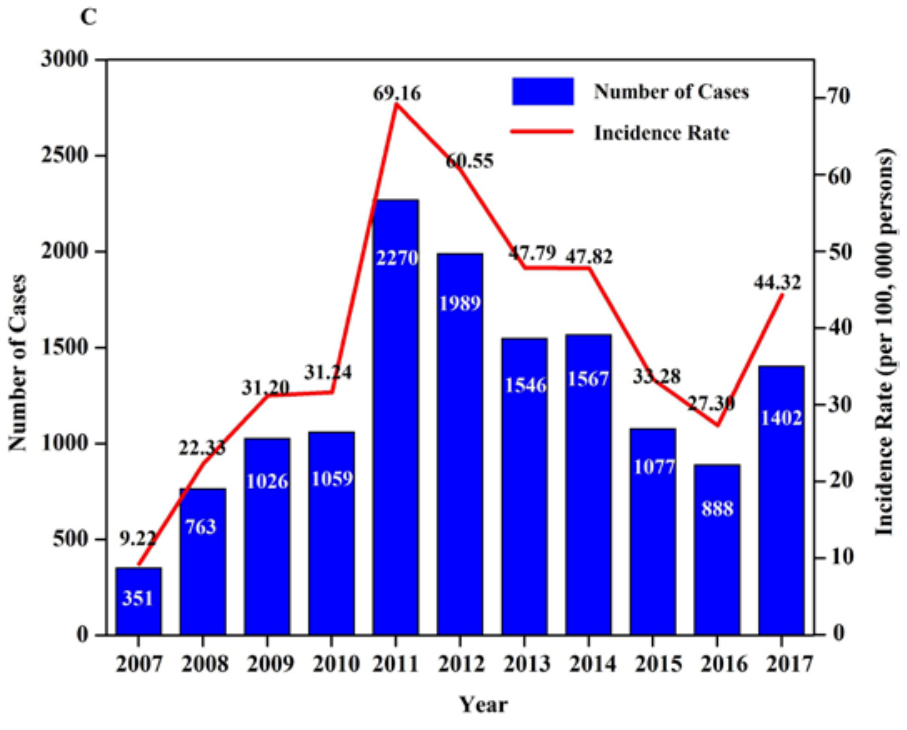

Figure 1 Demographic data of human brucellosis in Tongliao from 2007 to 2017. (A) The age distribution of the total reported cases. (B) The career distribution of human brucellosis over the 11-year period. (C) Annual reported cases and incidence rates of human brucellosis in Tongliao, 2007-2017.

patients $(n=3824)$ with a sex ratio of 2.64. The occupational distribution of human brucellosis over the 11-year period in Tongliao was also analysed. As shown in figure $1 \mathrm{~B}$, the majority of the patients were agriculturalists and pastoralists, who accounted for $81.9 \%$ and $12.4 \%$ of cases, respectively (online supplementary table S2). No death report ascribed to the disease was observed during the study period.

The average annual incidence rate of human brucellosis was 38.56 per 100000 in Tongliao over 2007-2017. The lowest annual incidence rate was 9.22/100 000, which was seen in 2007 with 351 cases of the disease, and the peak was 69.16/100 000, in 2011 with 2270 cases. A sharp increase in the trend of the human brucellosis epidemic was seen during 2007-2011, and the annual increase in incidence rate was $14.99 \%$, whereas it decreased during 2012-2016 with an average annual decrease of $8.37 \%$. However, the incidence rate of human brucellosis tended to recover in recent years as it reached 44.32/100 000 in 2017 with 1402 reported cases (figure 1C).

\section{Seasonality of reported brucellosis cases}

A thermal table of monthly cases was used to describe the seasonality of human brucellosis (figure 2A). The maximum number of cases in a month was in May 2011 with 323 cases of the disease, and the minimum number was 11 cases, in November and December 2007. There was an apparent seasonality of human brucellosis, and the highest incidence reported was from March to July accounting for $58.6 \%(\mathrm{n}=8162)$ of the total cases during the study period. The number of monthly cases reported peaked in April with a total of 1891. However, it trended to monthly anterior displacement since 2012, with a huge number of cases $(14.0 \%-25.6 \%)$ seen in January and February during 2012-2017. The time series analysis model indicated that a periodic trend of monthly cases reported was found in nearly all of the study years, and there was a trend to rise first, then fall and rise again from 2007 to 2017 (figure 2B).
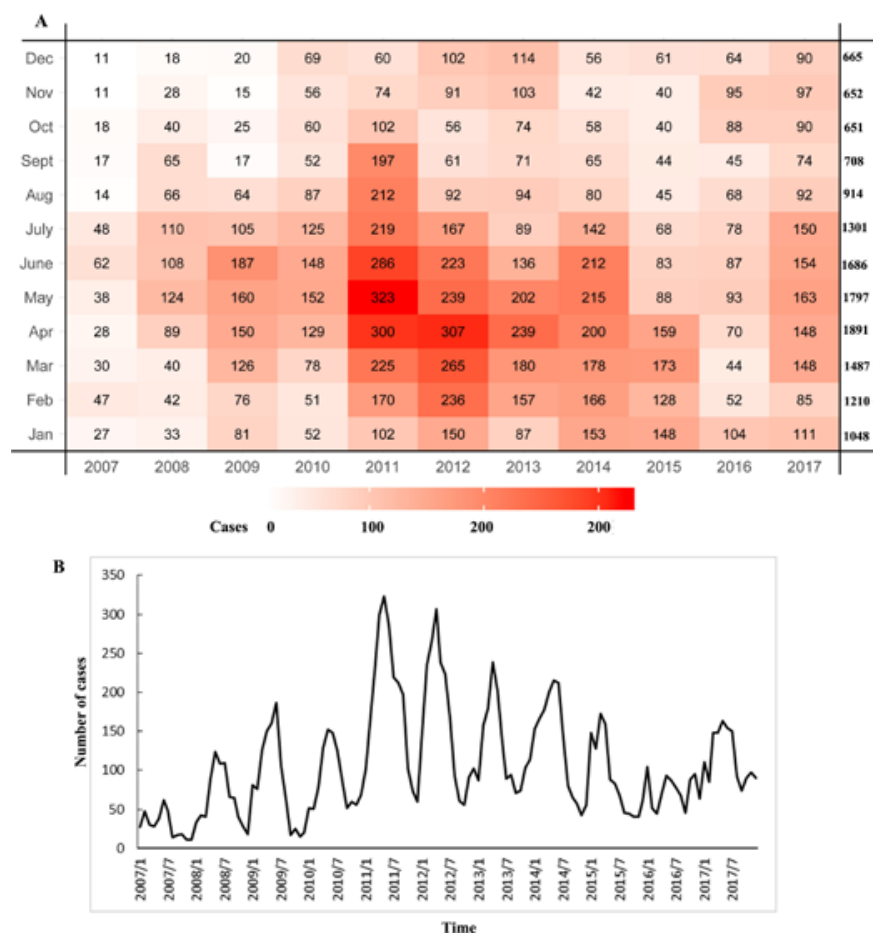

Figure 2 Analysis of the seasonal features of reported brucellosis cases during 2007-2017. (A) The thermal map of monthly reported cases of human brucellosis in Tongliao city. (B) The time series analysis model of the cycle and trend of the monthly reported cases. 


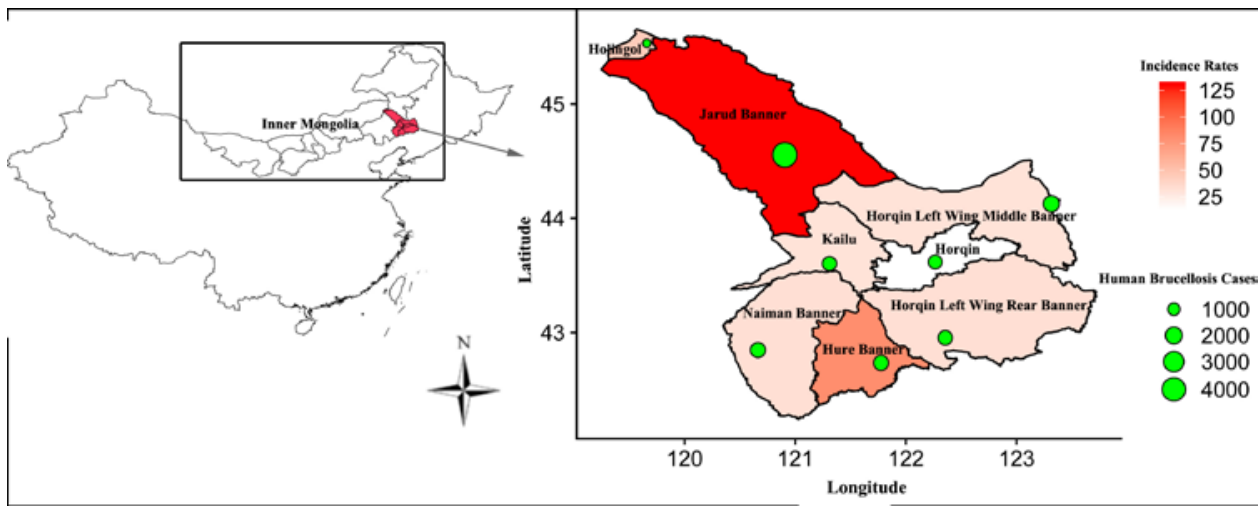

Figure 3 County-level spatial distribution of reported cases and incidence rates (cases per 100000 population) of human brucellosis during 2007-2017.

\section{Geographical distribution}

Figure 3 shows the spatial distribution of the accumulated cases and average incidence rates over 2007-2017 at county level. Seven out of eight counties had an accumulated incidence rate over 20/100 000. The highest incidence rate during the study period (130.1/100 000) was found in Jarud Banner, the area located in northwestern Tongliao, accounting for $32.3 \%$ of the total cases $(\mathrm{n}=4501)$. The fewest reported cases were in Holingol $(n=413)$ as its population totals are much lower than other counties, while the lowest incidence rate $(13.1 \%)$ was reported in Horqin during 2007-2017 (online supplementary tables S3 and S4).

The incidence rates and cases were further mapped in figure 4 and online supplementary figure S1. The annual rates continuously increased from 56.8 to 212.9 per 100000 from 2007 to 2011 (with cases increasing from 188 to 688) in Jarud Banner, and the region had the highest accumulated rates. The incidence decreased to $55.8 / 100000 \quad(\mathrm{n}=168)$ in 2016 followed by a slight elevation in $2017(87.11 / 100000, \mathrm{n}=253)$. However, there was an outbreak of human brucellosis in Hure

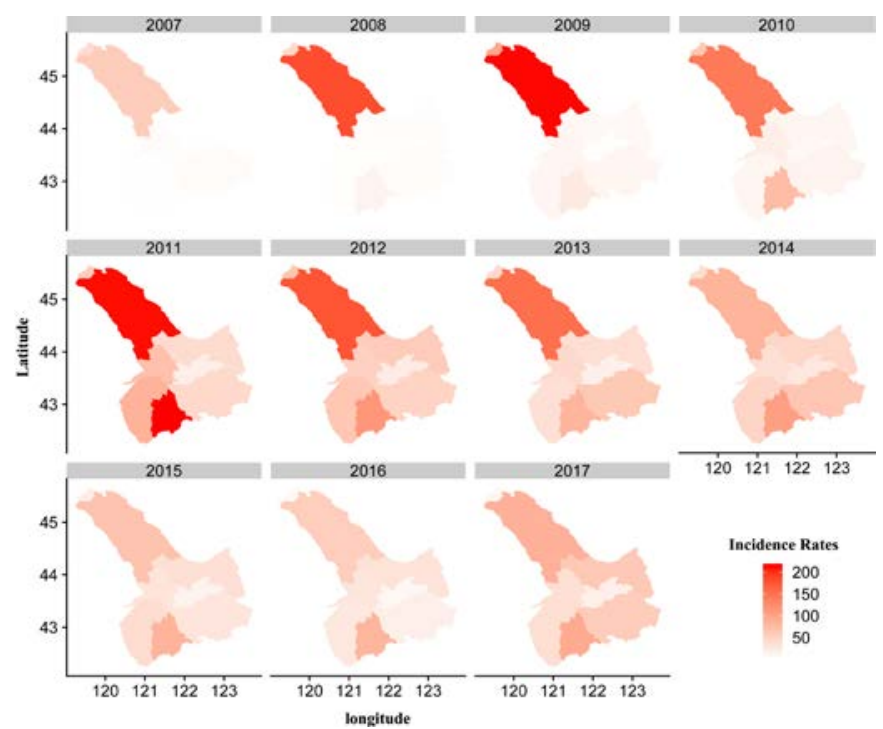

Figure 4 The annual incidence rates of human brucellosis cases in Tongliao City.
Banner, the area located in south-western Tongliao, with the highest incidence rate (213.8/100 000 with 369 cases) in 2011, although that was constantly low during 2007-2010 (2.2 to 75.6 per 100000 ), and it maintained higher incidence rates during 2012-2017 (81.9 to 114.9 per 100000 ) compared with other counties. The incidence rates and number of cases in nearly all of the counties decreased since 2012 except for a slight restoration in 2017. In 2007, only two counties had incidence rates over 30.0/100 000 (Jarud Banner and Holingol), the areas located in north-western Tongliao. However, the high-risk areas shifted southwards and eastwards, and the counties with incidence rates greater than 30.0/100000 increased to seven in 2011 (online supplementary tables S3 and S4). The difference in the incidence rates between the west and the east gradually lessened over the study period.

\section{DISCUSSION}

The transmission of human brucellosis has received extensive attention in China, especially in Inner Mongolia. ${ }^{13}$ However, the epidemiological characteristics of human brucellosis in Tongliao city, one of the high-risk areas in Inner Mongolia, has not been well studied. In the present study, data accumulated in Tongliao were extracted to describe demographic characteristics, seasonality and spatiotemporal distribution of reported human brucellosis at the county level from 2007 to 2017. This study may provide some inspirations for the allocation of brucellosis-related healthcare resources and the exploitation of control strategies.

Based on the results of this study, a total of 13938 cases of human brucellosis in Tongliao over the last 11 years contributed to approximately $11.5 \%$ of all the cases reported in Inner Mongolia. ${ }^{4}$ The general trend of temporal variations in Tongliao during 2007-2011 showed an increase over time, especially in counties located in the north-western regions, which was similar in neighbouring cities such as Shilingol, Chifeng and Hinggan in Inner Mongolia. ${ }^{6914}$ The increase in cases could be attributed to the rapid development of 
livestock trading, especially goat and sheep breeding during this period, ${ }^{815}$ as more than $90 \%$ of human brucellosis in China was transmitted from infected goat and sheep directly or indirectly. ${ }^{16-18}$ Whereas, from the historical variations perspective, the increase of accessibility sanitation facilities, as well as the development of diagnostic and reporting networks since 2003, might be partly responsible for the visual increase of human brucellosis during 2007-2011. ${ }^{9} 19$

The annual incidence rates moderately decreased during 2012-2016. Some control strategies like systematic examination of livestock, disinfection of milk, control of animal trade and slaughter, and quarantine measures were conducted in Tongliao and other regions in Inner Mongolia during this period. Besides, the comprehensive health education programme might also contribute to the decrease in incidence rates, and it was reported that the awareness rate of brucellosis among the high-risk population apparently increased in Inner Mongolia (from $73.2 \%$ to $87.4 \%$ during 2010-2014).$^{20}$ More importantly, mass vaccination of all sexually mature sheep with Rev 1 live strain vaccine twice a year was required by the government since 2011, resulting in a reduced number of cases of the disease during this period. However, human brucellosis in Tongliao and even in Inner Mongolia has hardly been eliminated, as it is concluded that brucellosis could persist for a long period of time even though all sheep were supposedly vaccinated. ${ }^{21}$ A sustainable strategy for continued implementation of the planned measures is still lacking, and the infected sheep are still common across Tongliao. Procedure surveillance was also affected by misdiagnosis, reporting bias and imprecise symptoms. Finally, the insufficient strength of the eradication strategy could be due to the slight upswing of human brucellosis in 2017, which could not completely be ascribed to climate change. Researchers have predicted that brucellosis will gradually increase in the next decades and reach a peak at about 2030, using an available dynamic model of brucellosis transmission taking into account sheep population, vaccination and health education. ${ }^{4}$ Therefore, policy makers should take a different view of the comprehensive control strategies based on the optimal principle and find the right balance among several objectives, such as policy, resources and technique, to prevent spread of the disease. Simultaneous disinfection, vaccination and regular sheep surveillance, as well as health education and economic compensation for slaughtered animals has been suggested.

It is well known that occupational features, such as agriculture workers, herdsmen, abattoir workers and livestock dealers, were highly correlated with the occurrence of human brucellosis. ${ }^{22}{ }^{23}$ In the present study, agriculture was the major occupation in human brucellosis cases (accounting for $81.9 \%$ of total cases), and the herdsman occupied second position $(12.4 \%)$, which was consistent with previous reports in Inner Mongolia. ${ }^{24}$
About $70 \%$ of Tongliao's population is rural farmers and mainly live by grazing or agriculture. It is common for them to share living space with their livestock without effective personal protection, leading to easy exposure to infected livestock. ${ }^{25}{ }^{26}$ Numerous reports have indicated that human brucellosis occurred in a specific gender and age range ${ }^{27}$ In the present study, we expounded that human brucellosis could happen in any age stage (ranging from 1 year to 85 years) in Tongliao, but most of the cases were $25-59$ years old $(85.44 \%)$ with a sex ratio of 2.64 (male/female). The age and gender trends seem to be related to the occupation, as most of the population participating in risky practices are the primary money earners in rural families.

Human brucellosis can happen in any season or month during a year. However, a clear seasonality of human brucellosis was found in our study, and the epidemic seasons in Tongliao were late spring and the whole of summer, and were consistent with the reports in Inner Mongolia and other places. ${ }^{414}$ These seasons coincide with the cultivation and lambing times in Tongliao, indicating more opportunities of exposure to the infected livestock. The climate, such as temperature, length of sunshine and rainfall, has been demonstrated to be highly correlating with brucellosis transmission in China. ${ }^{16}$ Warmer temperature and higher humidity during March to July in Tongliao are also suitable for the spread of infection. ${ }^{428}$ However, we also found a monthly anterior displacement of the high incidence of human brucellosis since 2012, which could be ascribed to the climate change in these years. Therefore, it is necessary to post warnings before the epidemic season, which may be effective in protecting the high-risk groups from infection and seeking medical assistance in time.

The geographical distribution analysed at county level during the study period indicated that the highest risk area of human brucellosis was Jarud Banner, located in northwestern Tongliao. This area is well known for its extensive prairies and livestock, containing approximately $40.2 \%$ of the total cattle and sheep in Tongliao during 2009-2015, and is larger than any other county. In our opinion, living habits, medical conditions and education level might affect the distribution of the disease. Most of the patients were living in rural areas with lower prevention awareness and far from the Center of Disease Control and Prevention (CDCs), the most important of disease prevention and monitoring units in China, leading to the increased risk of infection and inaccessible treatment service. Otherwise, the annual incidence rates were maintained at lower levels during the study period in Horqin (2.7 to 22.3 per 100000 ), the administration centre of Tongliao, a region with a higher degree of modernisation and level of medical education. More research should explore the factors impacting spatial spread of the disease.

\section{Strengths and limitations of this study}

This is the first study focusing on epidemiological characteristics of human brucellosis at county level during the past 11-year period in Tongliao city. Demographic data, 
seasonality and spatiotemporal distribution of reported brucellosis cases were explored to provide evidence for control strategies. However, there are several limitations in this study. First, the data were collected through passive public health surveillance. With regard to the untypical symptoms of some human brucellosis and inaccessible health facilities for some patients, data may be influenced by under-reporting, laboratory misdiagnosis and incomplete information. ${ }^{29}{ }^{30}$ Second, as human brucellosis is a zoonotic disease which is affected by many factors, such as the density of livestock, meat yield, slaughter amount and environment, a dynamic model including the abovementioned factors needs to be taken into account for brucellosis transmission and prediction, but these data could not be obtained in the present study. Lastly, the data of the pathogen types in the study were not available.

\section{CONCLUSIONS}

In conclusion, the epidemic of human brucellosis in Tongliao was aggravated during the past decade and peaked during the months from March to July with clear seasonality. High-risk areas were concentrated in the counties with extensive prairies and livestock. More research is required to clarify the burden of human brucellosis and to mobilise greater resources for disease elimination. Human brucellosis can be controlled by reducing the breeding size of livestock or enhancing the culling rate of infectious livestock. However, the government should find the right balance among several control problems in epidemics, although the quarantine-slaughter-immunisation strategy had been proven effective in the past decades.

\section{Author affiliations}

${ }^{1}$ Department of Anatomy, The Medical College of Inner Mongolia University for the Nationalities, Tongliao, Inner Mongolia, China

${ }^{2}$ Department of Respiratory Medicine, Affiliated Hospital of Inner Mongolia University for The Nationalities, Tongliao, Inner Mongolia, China

${ }^{3}$ Brucellosis Prevention and Treatment Engineering, Technology Research Center of Mongolia Autonomous region, Tongliao, Inner Mongolia, China

${ }^{4}$ Institute of Applied Anatomy, The Medical College of Inner Mongolia University for the Nationalities, Tongliao, Inner Mongolia, China

${ }^{5}$ Department of Thoracic Surgery, Affiliated Hospital of Inner Mongolia University for The Nationalities, Tongliao, Inner Mongolia, China

Acknowledgements The authors thank the First Institute of Endemic Diseases Prevention in Jilin Province, China, for their support.

Contributors All authors took part in the design and planning of the study. DL and $B Z$ collected the data. DL, LL, JZ and LW analysed the data. DL drafted the manuscript. BZ conceived and designed the study.

Funding This study was supported by the Brucellosis Prevenyion and Treatment Engineering Technology Research Center of Mongolia Autonomous region open issue (no. MDK2018052) and the National Natural Science Foundation of China (no. 81873313).

Map disclaimer The depiction of boundaries on this map does not imply the expression of any opinion whatsoever on the part of $B M J$ (or any member of its group) concerning the legal status of any country, territory, jurisdiction or area or of its authorities. This map is provided without any warranty of any kind, either express or implied.
Competing interests None declared.

Patient consent for publication Not required.

Provenance and peer review Not commissioned; externally peer reviewed.

Data availability statement Data are available upon reasonable request. All data relevant to the study are included in the article or uploaded as supplementary information.

Open access This is an open access article distributed in accordance with the Creative Commons Attribution Non Commercial (CC BY-NC 4.0) license, which permits others to distribute, remix, adapt, build upon this work non-commercially, and license their derivative works on different terms, provided the original work is properly cited, appropriate credit is given, any changes made indicated, and the use is non-commercial. See: http://creativecommons.org/licenses/by-nc/4.0/.

ORCID iD

Bin Zhang http://orcid.org/0000-0003-4318-8560

\section{REFERENCES}

1 Mugizi DR, Boqvist S, Nasinyama GW, et al. Prevalence of and factors associated with Brucella sero-positivity in cattle in urban and peri-urban Gulu and Soroti towns of Uganda. J Vet Med Sci 2015;77:557-64.

2 Chatterjee P, Bhaumik S, Chauhan AS, et al. Protocol for developing a database of zoonotic disease research in India (DoZooRI). BMJ Open 2017;7:e017825.

3 Alves AJS, Rocha F, Amaku M, et al. Economic analysis of vaccination to control bovine brucellosis in the States of Sao Paulo and Mato Grosso, Brazil. Prev Vet Med 2015;118:351-8.

4 Zhou L, Fan M, Hou Q, et al. Transmission dynamics and optimal control of brucellosis in Inner Mongolia of China. Math Biosci Eng 2018;15:543-67.

5 Lai S, Zhou H, Xiong W, et al. Changing epidemiology of human brucellosis, China, 1955-2014. Emerg Infect Dis 2017;23:184-94.

6 Zhong Z, Yu S, Wang X, et al. Human brucellosis in the people's Republic of China during 2005-2010. Int J Infect Dis 2013;17:e289-92.

7 Guan P, Wu W, Huang D. Trends of reported human brucellosis cases in mainland China from 2007 to 2017: an exponential smoothing time series analysis. Environ Health Prev Med 2018;23:23.

8 Chen Q, Lai S, Yin W, et al. Epidemic characteristics, high-risk townships and space-time clusters of human brucellosis in Shanxi Province of China, 2005-2014. BMC Infect Dis 2016;16:760.

9 Jia P, Joyner A. Human brucellosis occurrences in inner Mongolia, China: a spatio-temporal distribution and ecological niche modeling approach. BMC Infect Dis 2015;15:36.

10 Liang C, Wei W. [Epidemiological, Occupational Characteristics and Clinical Manifestation of Occupational Forest Encephalitis in HunlunBuir city during 2008-2017]. Zhonghua Lao Dong Wei Sheng Zhi Ye Bing Za Zhi 2018;36:597-9.

11 Zeng $\mathrm{H}$, Wang $\mathrm{Y}$, Sun $\mathrm{X}$, et al. Status and influencing factors of farmers' private investment in the prevention and control of sheep brucellosis in China: A cross-sectional study. PLoS Negl Trop Dis 2019;13:e0007285.

12 Cao N, Guo SY, Yan T, et al. Epidemiological survey of human brucellosis in inner Mongolia, China, 2010-2014: a high risk groupsbased survey. J Infect Public Health 2018;11:24-9.

13 Chen Z, Zhang W, Ke Y, et al. High-risk regions of human brucellosis in China: implications for prevention and early diagnosis of travelrelated infections. Clin Infect Dis 2013;57:330-2.

14 Zhang J, Yin F, Zhang T, et al. Spatial analysis on human brucellosis incidence in mainland China: 2004-2010. BMJ Open 2014;4:e004470.

15 Chen J-diao, Ke C-W, Deng X, et al. Brucellosis in Guangdong Province, People's Republic of China, 2005-2010. Emerg Infect Dis 2013;19:817-8.

16 Li Y-J, Li X-L, Liang S, et al. Epidemiological features and risk factors associated with the spatial and temporal distribution of human brucellosis in China. BMC Infect Dis 2013;13:547.

17 Patra S, Ke V, Tellapragada C, et al. Human brucellosis: experience from a tertiary care hospital in southern India. Trop Doct 2018;48:368-72.

18 Cui B. The epidemic situation and prevention countermeasures of brucellosis in China. Zhonghua Yu Fang Yi Xue Za Zhi 2014;48:1035-8.

19 Ayoola MC, Akinseye VO, Cadmus E, et al. Prevalence of bovine brucellosis in slaughtered cattle and barriers to better protection of 
abattoir workers in Ibadan, south-western Nigeria. Pan Afr Med $J$ 2017;28.

20 Cui B. Brucellosis epidemiology and prevention measures in China. China Prev Med 2014;42:1035-8.

21 Hou Q, Sun X, Zhang J, et al. Modeling the transmission dynamics of sheep brucellosis in Inner Mongolia Autonomous Region, China. Math Biosci 2013;242:51-8.

22 Madzingira O, Sezuni PM. Serological prevalence and public health significance of brucellosis on a dairy farm in Namibia from 2011 to 2014. BMC Res Notes 2017;10:620.

23 Awah-Ndukum J, Mouiche MMM, Kouonmo-Ngnoyum L, et al. Seroprevalence and risk factors of brucellosis among slaughtered indigenous cattle, abattoir personnel and pregnant women in Ngaoundéré, Cameroon. BMC Infect Dis 2018;18:611.

24 Zhang W-Y, Guo W-D, Sun S-H, et al. Human brucellosis, inner Mongolia, China. Emerg Infect Dis 2010;16:2001-3.
25 Cheng XP, Zhou YB, Xiao-Wei LI, et al. Analysis of influencing factors about brucellosis among ocupational groups in Western Liaoning Province. J Occup Environ Med 2010;27:314-6.

26 Cash-Goldwasser S, Maze MJ, Rubach MP, et al. Risk factors for human brucellosis in northern Tanzania. Am J Trop Med Hyg 2018;98:598-606.

27 Khan M, Zahoor M. An overview of brucellosis in cattle and humans, and its serological and molecular diagnosis in control strategies. TropicalMed 2018;3:e65.

28 Hou Q, Sun X, Zhang J, et al. Modeling the transmission dynamics of sheep brucellosis in inner Mongolia autonomous region, China. Math Biosci 2013;242:51-8.

29 ElTahir Y, Al Toobi AG, Al-Marzooqi W, et al. Serological, cultural and molecular evidence of Brucella melitensis infection in goats in $\mathrm{Al}$ Jabal Al Akhdar, Sultanate of Oman. Vet Med Sci 2018.

30 Elzein FE, Al Sherbini N, Alotaibi MM, et al. Brucellosis accompanied by haemophagocytic lymphohistiocytosis and multiple splenic abscesses in a patient with depression. BMJ Case Rep 2018;6. 